\title{
Incision length: an emerging risk factors for surgical-site infection following cesarean section
}

\author{
Tripti Nagaria ${ }^{1}$, Avinashi Kujur ${ }^{1 *}$, Neha Thakur ${ }^{2}$ \\ ${ }^{1}$ Department of Obstetrics and Gynecology, Pt.J.N.M.Medical College, Raipur, Chhattisgarh, India \\ ${ }^{2}$ Department of Obstetrics and Gynecology, Government Medical College, Rajnandgaon, Chhattisgarh, India
}

Received: 04 April 2017

Accepted: 08 April 2017

\author{
*Correspondence: \\ Dr. Avinashi Kujur, \\ E-mail: avinashikujur@gmail.com
}

Copyright: ( $)$ the author(s), publisher and licensee Medip Academy. This is an open-access article distributed under the terms of the Creative Commons Attribution Non-Commercial License, which permits unrestricted non-commercial use, distribution, and reproduction in any medium, provided the original work is properly cited.

\section{ABSTRACT}

Background: Since late nineteenth century, the caesarean section first done there is a tremendous improvement in the surgical and anaesthetic skills. It has emerged as a safe mode of delivery but now, in the present era there is a continuous rising trend of caserean section. Objective of present study is to evaluate the effect of some specific gestational factors and other known variables associated with poor wound healing in women who delivered by cesarean section.

Methods: A total of 1215 women delivered by cesarean section at Pt. JNM Medical college, Raipur, Chhattisgarh, India from May 2014 to April 2015 were included in this study. The BMI was measured at gestational age when she got operated, grade of surgeons was noted. Subcutaneous tissue depth was intra-operatively measured from the fascia to the skin surface, while the incision length was measured after skin closure.

Results: Out of 1215 women operated 251 cases developed SSI with incidence of $20.5 \%$. Incision length (OR 2.40, 95\% CI 2.11-2.73; p<0.0001), Body mass index (BMI) at term (OR 2.9, 95\% CI 1.82-4.44; <0.0001), previous caesarean section scar (OR 0.72, 95\% CI 0.54-0.96; $\mathrm{p}=0.02$ ), Grade of surgeon (OR 5.5, 95\% CI 3.3-9.3; p<0.0001), subcutaneous tissue thickness (OR 1.88, 95\% CI 1.60-2.23, p<0.0001) were found to be correlated with wound complications. The receiver operating characteristics curve analysis suggested a cut-off of 28.7 for the BMI at term with AUC $0.8(0.79-0.84, \mathrm{p}<0.0001)$ and $147 \mathrm{~mm}$ for the wound length with an AUC 0.8 (95\% CI 0.78-0.82; p $<0.0001)$. The multivariate logistic regression model, applied to these variables showed an independent correlation of incision length with SSI incision length $>14.7$; OR $2.40,95 \%$ CI 2.11-2.73, p $<0.0001$.

Conclusions: Incision length by itself was found to be an independent risk factor for development of surgical site infection.

Keywords: BMI, Incision length, Surgeon skill, Surgical site infection

\section{INTRODUCTION}

Since late nineteenth century, the caesarean section first done there is a tremendous improvement in the surgical and anaesthetic skills. It has emerged as a safe mode of delivery but now, in the present era there is a continuous rising trend of caserean section. ${ }^{1}$ Apart from the minimal inherent risk of any surgical procedure, the surgical site infection is the significant cause of post surgical morbidity and can be described as an indicator for surgical quality; particularly in developing countries.

According to CDC's National Nosocomial Infection Survillence system $38 \%$ of all nosocomial infections in surgical patients are SSI. They constitute third most common nosocomial infection. ${ }^{2}$ The rates of SSI after caesarean deliveries range from the incidence varies from 0.5 to $15 \%$ depending on the type of operation, 
underlying patient status associated co morbidities and surveillance methods used to identify infections, studies in India have consistently shown higher rates ranging from $23-28 \% .^{3,4}$

The CDC definition describes three levels of surgical site infection, superficial incisional affecting the skin and subcutaneous tissue, deep incisional, which affects the facial and muscle layers and organ or space infection which involves any part in the body other than the incision that is opened or manipulated during the surgical procedure. $^{5}$

Knowledge regarding risk factors for SSI is mandatory; to develop prevention strategies and further reducing risk of infection. A number of risk factor predispose a woman to suffer from wound complication i.e. obesity, medical disorders, gestational anaemia, inter current infection, surgical asepsis, use of peri operative antibiotics, skills of surgeons and operative techniques.

\section{METHODS}

Present study was carried out in Department of Obstetrics and Gynaecology of Pt. Jawaharlal Nehru Medical College, Raipur from May 2014 to April 2015.

The study was prospective observational study. A total of 1215 women undergoing caesarean section at our department were included, outside operated caesarean section and referred cases attending our hospital as SSI were excluded.

Data was collected from patients by using Performa. Written informed consent was obtained and data regarding age, BMI at term, parity, gestational age, previous scar, obstetric complications, presence of UTI, type of fetal presentation, type of anaesthesia, grade of surgeon, incision length, subcutaneous tissue thickness was collected. Direct wound observation was done from postoperative fourth day and was kept under observation till day of discharge.

A wound was defined complicated when there was at least one of the following sign: classical sign of infection (redness, duration, tenderness, fever, discharge), abscess, hematoma, wound dehiscence $>1 \mathrm{~cm}$. All the suspected cases of SSI were investigated and treated irrespective of day of operation until complete recovery. However, patient who developed infection after discharge were not included in the study due to incompleteness of follow up.

\section{Statistical analysis}

Continuous data were reported as mean and standard deviation while categorical data were reported as percentages. Correlation between the analyzed variables and the onset of wound complications were calculated by applying logistic regression analysis and the corresponding odds ratio (OR) and 95\% confidence interval are reported. All the statistically significant variables in the univariate analysis were included in a multivariate logistic regression model. The ROC (receiver operating characteristics) curve, applied to the continuous variables, and was used to get a area under curve (AUC), while in order to evaluate the cut off levels-suggested by ROC curve. A p value of $<0.05$ was considered significant.

\section{RESULTS}

Out of the 1215 women who underwent LSCS during the study period, 251 (20.5\%) women developed surgical site infection. The demographic characteristics of study population were as reported in Table 1 .

\section{Table 1: Demographic characteristics of the sample $(n=1215)$.}

\begin{tabular}{|c|c|}
\hline \multicolumn{2}{|l|}{ Demographic characteristics } \\
\hline Maternal age in years & $25 \pm 4.3$ \\
\hline Nulliparous & $43.2 \%$ \\
\hline BMI & $28.1 \pm 5.7$ \\
\hline Gestational age in weeks & $37.04 \pm 1.5$ \\
\hline Previous CS & $45.2 \%$ \\
\hline Presence of obstetric complications & $35.6 \%$ \\
\hline Presence of UTI & $11.8 \%$ \\
\hline Type of anesthesia (spinal) & $86.4 \%$ \\
\hline Fetal presentation (cephalic) & $88.3 \%$ \\
\hline Hemoglobin in gm/dl & $8.73 \pm 2.07$ \\
\hline Referral & $47.2 \%$ \\
\hline
\end{tabular}

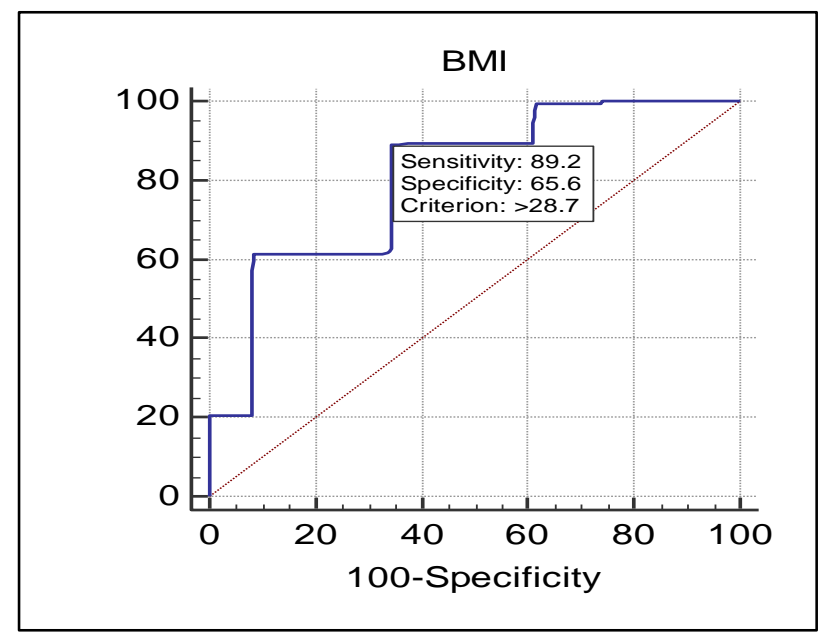

Figure 1: Receiver operating characteristics curve analysis applied for incision length. Dashed lines croSSIng the cut-off point $(28.7 \mathrm{~kg} / \mathrm{m} 2)$ indicates sensitivity $(89.2 \%)$ and specificity $(65.6 \%)$.

On analysis of various risk factors for wound complication, length of incision (OR 2.40, 95\% CI 2.112.73; $\mathrm{p}<0.0001)$, BMI at term (OR 2.9, 95\% CI 1.824.44 ; $<0.0001$ ), Grade of surgeon (OR 5.5, 95\% CI 3.39.3; $\mathrm{p}<0.0001$ ), previous caesarean section scar (OR 0.72 , 95\% CI 0.54-0.96; $\mathrm{p}=0.02$ ), subcutaneous tissue thickness 
(OR1.88, 95\% CI 1.60-2.23, p<0.0001) were found to be significantly correlated with wound complications (Table 2).

ROC curve analysis for BMI at term and incision length gave an AUC $0.8(0.78-0.82 ; \mathrm{p}<0.0001)$ of BMI at term, and $0.8(0.79-0.84, \mathrm{p}<0.0001)$ of incision length (Figure 1 and 2). Moreover, ROC curve suggested a cut-off of 28.7 for BMI at term and 14.7 for incision length. Logistic regression analysis was applied to the calculated cut-offs at term, OR $1.11(1.05-1.18 ; \mathrm{p}=0.0002)$ and for incision length, OR 2.89 (2.53-3.30; $\mathrm{p}<0.0001)$. The multivariate logistic regression analysis was applied to these variables which showed an independent correlation between these variables and surgical site infection (at term $\mathrm{BMI}>28.7$; OR 1.25, 95\% CI 1.21-1.29, $\mathrm{p}<0.0001$; wound length>14.7; OR 2.40, 95\% CI 2.11-2.73, p<0.0001).

Table 2: Analysis of risk factor for surgical site infection.

\begin{tabular}{|llllc|}
\hline Variable & & OR & CI 95\% & P \\
\hline BMI at term & Normal vs mild obese & 3.2 & $1.9-5.1$ & $<0.0001$ \\
\hline & Normal vs moderate obese & 5.15 & $3.2-8.1$ & $<0.0001$ \\
\hline & Normal vs severe obese & 8.1 & $4.8-13.7$ & $<0.0001$ \\
\hline Grade of operating surgeon & Normal vs undernourished & 0.4 & $0.38-107.5$ & 0.195 \\
\hline & Senior resident vs Consultant & 4.4 & $2.6-7.6$ & $<0.0001$ \\
\hline & Junior resident vs Consultant & 5.8 & $3.1-10.8$ & $<0.0001$ \\
\hline Previous scar & Junior resident vs Senior resident & 1.41 & $0.9-2.08$ & 0.083 \\
\hline Incision length & Previous scar vs no scar & 0.72 & $0.54-0.96$ & 0.02 \\
\hline Subcutaneous scar thickness & & 2.40 & $2.11-2.73$ & $<0.0001^{\mathrm{R}}$ \\
\hline
\end{tabular}

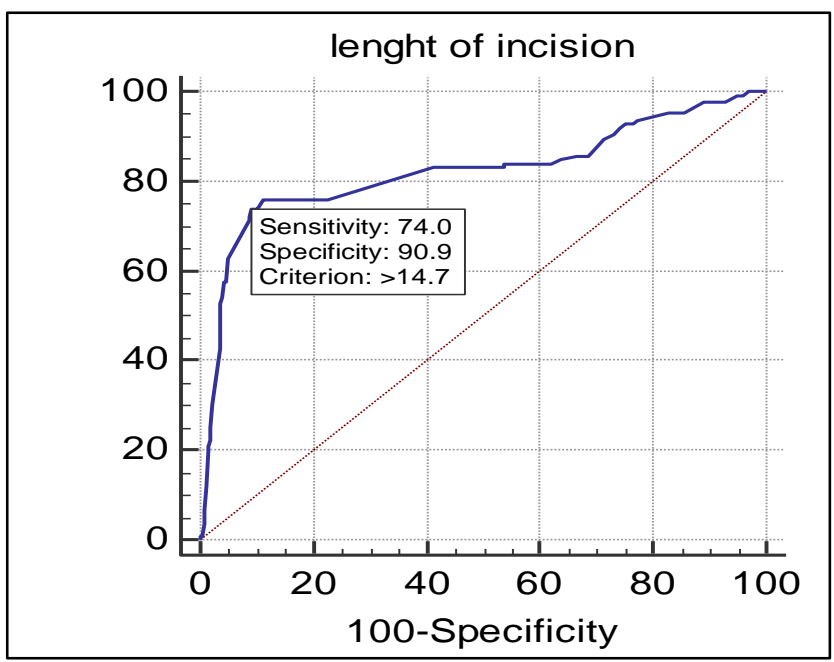

Figure 1: Receiver operating characteristics curve analysis applied for incision lenght. Dashed lines

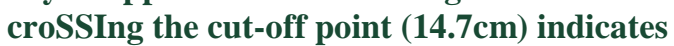
sensitivity (74\%) and specificity $(90.9 \%)$.

\section{DISCUSSION}

Surgical site wound infection is the most important associated morbidity with any kind of the surgery apart from the inherent risk of the surgery and the anesthesia. Cesarean section is one of the most common surgery practiced in present era in obstetric population. A rising trend in the caesarean section rate is observed all over the world in past 30 years. In 1980, the CS rate in England was $9 \%$, this increased to $13 \%$ in 1992 (Treffers PE et al), $21 \%$ in 2000 (RCOG), 23\% in 2004 (Stats Q et al) and $24.8 \%$ in 2009 (Department of Health). ${ }^{1}$ It has resulted in improvement in perinatal outcome but at the same time there is an increase in the postoperative morbidity particularly surgical site wound infection.

WHO has reported a SSI rate of 0.5 to $15 \%$ depending upon type of operation and underlying patient status. ${ }^{6}$ In present study, we observed incidence of SSI to be $20.5 \%$ (251 out of 1215) which is very high as compared to that observed by others. However, comparable to the incidence reported in our country i.e. 24.2\% (Table no 3), which is in line to present study. The risk for developing SSI after caesarean section is multi factorial. In the present study, a number of the variables had been studied which were likely to influence the rate of SSI and the results were captivating in respect to detection of new risk factor not taken in consideration previously.

In current study variables found to influence SSI and associated with poor wound healing were; BMI, incision length, grade of operating surgeon, previous scar, subcutaneous tissue thickness.

Interestingly, analysis of incision length never done before, found to be an important risk factor. The ROC curve generated for incision length described area under curve $0.8(0.79-0.84, \mathrm{p}<0.0001)$ giving a cut off of 14.7 , indicating a sensitivity of $74 \%$ and specificity of $90.9 \%$ This can be probably explained by extensive exposure to air borne and local contamination, prolong tissue handling, decreased local immunity, oxygen tension, 
surgical technique, with way to approximate wound. Greater length of incision leads to greater vascular disruption with negative impact on wound healing process. ${ }^{7}$ The surgeon's operating skills play a important role in wound infections. In present study, remarkable difference was seen in wound outcome when consultant and senior resident were compared,30 vs $221 \quad(<0.001)$, the rationale behind this may be because our hospital is a referral tertiary center and $3 / 4^{\text {th }}$ of the LSCS were done in the emergency hours (888/1215) when most of the Obstetric work is taken care of by the resident staff. Antiseptic technique in emergency hours may also be a limiting factor.

The next factor, BMI is an independent risk factor for developing the SSI (Table 4). ${ }^{8-12}$ The ROC curve generated in this study suggested a BMI at term cut-off point of 28.7 and AUC $0.8 \quad(0.78-0.82$; p <0.0001) indicating a sensitivity of $89.2 \%$, specificity of $65.6 \%$. The pathogenic mechanisms for predisposition of SSI in obese cesarean patients have been suggested to be tissue hypoperfusion (subcutaneous adipose tissue), a high ratio of tissue mass: capillaries in adipose tissue, larger wound surface areas and decreased oxygen tension in adipose tissues which may be together categorized as a poor balance between tissue oxygen demand and oxygen supply predisposing SSI through greater risk of ischemia/necrosis and suboptimal neutrophil oxidative killing. ${ }^{12}$

As obesity leads to subcutaneous tissue deposition the thickness of the subcutaneous fat is directly proportional to the BMI. Vermillion et al concluded that subcutaneous tissue thickness is the only significant risk factor associated with wound infection after ceasarean section. ${ }^{13}$

In present study, mean subcutaneous tissue thickness was $2.63 \pm 0.84$ (OR 1.88, 95\% CI 1.60-2.23, p<0.0001), other various studies have also confirmed a higher rate of SSI at a subcutaneous fat thickness of more than $2 \mathrm{~cm} .{ }^{14,15}$ The healing process in obese pregnant patients can be impaired by a greater production of proinflammatory mediators such as TNF- $\alpha$, IL- 6 and C-reactive protein, by the thick adipose tissue, the same factors are also predispose these obese cases for the development of Preeclampsia and GDM. ${ }^{16}$ This also shows the impact of the weight gain during pregnancy on wound healing. As it is one of the few risk factor which could not be avoided during labor; education for preconceptual weight loss and prophylactic antibiotic is recommended. ${ }^{17}$

In study, previous scared patients which were 550 out of which $98(40 \%)$ developed surgical site infection, and was significantly associated, probably scarred tissue lead to fibrosis and lack proper oxygen and blood supply and it also lack proper tissue approximation in next $\mathrm{C}$-section. Since previous cesarean delivery is most common and important indication for repeat caesarean section. The root solution for reduction of SSI in post caesarean deliveries is to reduce the caesarean section rate by increasing the rate of vaginal delivery whenever possible if, caesarean is not indicated. ${ }^{18}$ With the doubling caesarean section rate it has now became mandatory to improve our obstetrical services by understanding the pathophysiology of these risk factors in women. Development of surgical site infection after cesarean delivery is a morbid event and results in inconsequential patient discomfort, inconvenience. and degrading, prolong hospital stay, additional surgery, putting a psychological, economical and social burden on individual and community care.

\section{CONCLUSION}

BMI, Gestational age, previous scar, subcutaneous thickness is independent risk factor for SSI, they all together by influencing the length of incision, thereby contributing significantly towards SSI. Incision length is itself an independent risk factor for development of surgical site infection

Therefore, giving careful and appropriate incision length, monitoring gestational BMI, bringing professionalism in surgeon skills and encouraging an attempt for vaginal delivery before taking decision for caesarean section.

\section{ACKNOWLEDGEMENTS}

The authors are thankful to all the women included in the study, faculty and technical staff of department of Obstetrics and gynaecology, Dr. BRAM Hospital, Pt. J. N. M. medical college, Raipur (C.G.) India, for their cooperation and support during the entire study period. Authors acknowledge the immense help received from the scholars whose articles are cited and included in references of this manuscript. The authors are also grateful to authors/editors/publishers of all those articles, journals and books from where the literature for this article has been reviewed and discussed

Funding: No funding sources

Conflict of interest: None declared

Ethical approval: The study was approved by the Institutional Ethics Committee

\section{REFERENCES}

1. NICE guidelines [CG132]. Caesarean Section. Clinical Guideline. London: RCOG; 2011.

2. National Nosocomial Infections Surveillance (NNIS). System Report, data summary from January 1992 through June 2004, issued October 2004. Am J Infect Control. 2004;32(8):470-85.

3. Srun S, Sinath Y, Seng AT, Chea M, Borin M, Nhem $\mathrm{S}$ et al. Surveillance of post-caesarean surgical site infections in a hospital with limited resources, Cambodia. J Infect Dev Ctries. 2013;7:579-85.

4. Ganguly PS, Khan Y, Malik A. Nosocomial infection and hospital procedures. Indian J Common Med. 2000;990-1014. 
5. CDC/NHSN Surveillance definitions for specific types of infections. January 2015. Available from https://www.cdc.gov/nhsn/pdfs/pscmanual/17pscnosi nfdef_current.pdf

6. WHO. Prevention of hospital acquired infections. A practical guide. 2nd edition; 2002 WHO/CDS/CSR/EPH/200212. Geneva: World Health Organization.

7. Waldorf H, Fewkes J. Wound healing. Adv Dermatol. 1995;10:77-96.

8. Myles TD, Gooch J, Santolay J. Obesity as an independent risk factor for infectious morbidity in patients who undergo cesarean delivery. Obstet Gynecol. 2002;100:959-64.

9. Anaya DA, Dellinger EP. The obese surgical patient: a susceptible host for infection Surg Infect (Larchmt). 2006;7(5):473-80.

10. Wall PD, Deucy EE, Glantz JC, Pressman EK. Vertical skin incisions and wound complications in the obese parturient. Obstet Gynecol. 2003;102:9526.

11. Perlow JH, Morgan MA. Massive maternal obesity and perioperative cesarean morbidity. Am J Obstet Gynecol. 1994;170(2):560-5.

12. Conroy K, Koenig AF, Yu Y, Courtney A, Lee HJ, Norwitz ER et al. Infectious morbidity after cesarean delivery: 10 strategies to reduce risk. Rev Obstet Gynecol. 2012;5(2):69-77.
13. Vermillion ST, Lamoutte C, Soper DE, Verdeja A. Wound infection after cesarean: effect of subcutaneous tissue thickness. Obstet Gynecol. 2000;95:923-6.

14. Naumann RW, Hauth JC, Owen J, Hodgkins PM, Lincoln T. Subcutaneous tissue approximation in relation to wound disruption after cesarean delivery in obese women. Obstet Gynecol. 1995;85(3):412-6.

15. Cetin A, Cetin M. Superficial wound disruption after cesarean delivery: effect of the depth and closure of subcutaneous tissue. Int $\mathbf{J}$ Gynaecol Obstet. 1997;57(1):17-21.

16. Wolf M, Kettyle E, Sandler L, Ecker JL, Roberts J, Thadhani R. Obesity and preeclampsia: the potential role of inflammation. Obstet Gynecol. 2001;98(5 Pt 1):757-62.

17. CMACE/RCOG Joint Guidelines. Management of Women with Obesity in pregnancy.; March 2010

18. Dodd JM, Crowther CA, Huertas E, Guise JM, Horey D. Planned elective repeat caesarean section versus planned vaginal birth for women with a previous caesarean birth. Cochrane Database Syst Rev. 2004;(4):CD004224.

Cite this article as: Nagaria T, Kujur A, Thakur N. Incision length: an emerging risk factors for surgicalsite infection following cesarean section. Int J Reprod Contracept Obstet Gynecol 2017;6:1829-33. 